\title{
Análise do capital social gerado no perfil @FasAmazonas
}

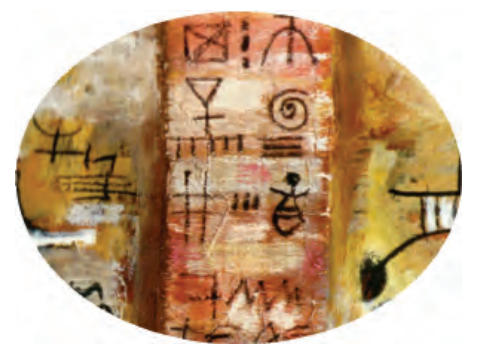

\author{
Jonas da Silva Gomes Jr.* \\ Denize Piccolotto Carvalho Levy **
}

\section{Resumo}

Este trabalho analisa o capital social gerado na rede social digital do perfil do Twitter da Fundação Amazonas Sustentável (@FasAmazonas). Para tanto, apresenta-se brevemente a discussão sobre redes sociais digitais e Twitter e algumas definições sobre capital social. São expostos ainda os elementos operadores (categorias) do conceito de capital social nas redes sociais. Os procedimentos metodológicos utilizados na pesquisa foram: observações (assistemáticas e sistemáticas), apreciação de perfis (seguido e seguidores) e análise de 300 atualizações. Os resultados da pesquisa apontam para existência de um denso circuito comunicativo em virtude das diferentes formas de Capital Social e uma multiplicidade de valores, interesses e motivações em torno do ato de seguir o@FasAmazonas.

Palavras-chave: Twitter; rede social digital; capital social; fundação Amazonas sustentável.

\footnotetext{
* Mestre em Ciências da Comunicação pela Universidade Federal do Amazonas (UFAM). Professor dos Cursos de Relações Públicas (UFAM) e Publicidade e Propaganda (Faculdade Martha Falcão). E-mail: jonasjr1@gmail.com / www.jonasjr.com

** Professora do Programa de Pós-Graduação em Ciências da Comunicação (PPGCCOM-UFAM). Pós-doutorada em Tecnologia Educacional na Universitat de les Illes Balears (2007). E-mail: piccolottolevy@gmail.com.
} 


\section{Abstract}

This paper analyzes the social capital generated in the digital social network Twitter profile of the Amazonas Sustainable Foundation (@FasAmazonas). It presents briefly the discussion of social networks and Twitter and some definitions of social capital. Elements are exposed even operators (categories) of the concept of social capital in social networks. The methodological procedures used in the research were: observations (systematic and unsystematic) assessment profile (followed and followers) and analysis of 300 updates. The survey results point to the existence of a dense circuit communication due to different forms of capital and a multiplicity of values, interests and motivations around the act of following the@ FasAmazonas.

Keywords: Twitter; social networking; social capital; fundação Amazonas sustentável.

\section{Introdução}

O Twitter (http:/ /www.twitter.com) é o microblog mais utilizado atualmente. Segundo O’ Reilly e Milstein (2009, p.13), "o serviço de comunicação foi criado em março de 2006 pela Obvious e inicia-se como um "projeto sem grandes pretensões, idealizado por uma empresa de podcasting ${ }^{1}$ de São Francisco, e não demorou para se tornar o principal projeto dela".

A dinâmica do site está no envio de "tweets" (atualizações) de até 140 caracteres em resposta ao questionamento-chave "O que está acontecendo?". Nota-se que há uma multiplicidade de respostas, demonstrando diferentes apropriações e adaptações ao sistema tecnológico-informacional.

No Twitter, os atores são identificados com o símbolo “@” seguido do nome de sua escolha, “@nome”. Um ator escolhe "seguir” outro, dessa forma ele passa a acompanhar as atualizações que são publicadas. $O$ ator "seguido" é, por conseguinte, notificado por e-mail que alguém o está seguindo, assim tem-se duas listas: uma com a relação de pessoas que seguem (se-

214 Somanlu, ano 11, n. 1, jan./jun. 2011 
guidores / followers) e outras com aqueles que são seguidas (following / seguidos). Dessa forma, a estrutura do microblog proporciona a existência de ambientes comunicacionais midiáticos por meio da interação e, posteriormente, a geração de laços sociais (RECUERO, 2009).

O microblog tem sido utilizado para as mais diversas funcionalidades, ocupando espaços mercadológicos, sociais, políticos, econômicos e culturais. A ferramenta tem sido utilizada ainda por diversas organizações que defendem as causas ambientais, como o Greenpeace e WWF. Na região amazônica, a Fundação Amazonas Sustentável (FAS) ${ }^{2}$ também faz uso de uma conta dessa ferramenta para alcançar seus propósitos.

Este trabalho dá continuidade a estudos já realizados (GOMES JR e LEVY, 2011) ${ }^{3}$ e tem como objetivo principal analisar o Capital Social gerado por meio do perfil da @FasAmazonas. O capital social é um elemento-chave para a compreensão dos padrões de conexão entre os atores sociais na Internet. O conceito auxilia na compreensão dos laços sociais e do tipo de rede social formada através das ferramentas sociais observadas na Internet. Busca-se, assim, nesta investigação compreender os fatores que potencialmente garantem as conexões entre atores nas redes sociais mediadas pelo computador.

\section{Redes sociais digitais e twitter}

Contemporaneamente, o termo "redes sociais" tem sido exaustivamente propagado nos espaços midiáticos, criando-se uma sensação de ineditismo e até mesmo deslumbramento tecnológico. As redes sociais, assim, passaram a ser concebidas "como produto da intervenção e interação humanas sobre a materialidade tecnológica" (COGO e BRIGNOL, 2011, p. 79). Dessa feita, o termo tem passado por um apagamento de sua dimensão histórica (FELINTO, 2011).

Sousa (2007, p.119) diz que "as redes sociais conduzem a uma nova abordagem de pesquisa social com ênfase nas relações entre diversas unidades de interação, não só o indivíduo de forma isolada e independente". $\mathrm{Na}$ visão de García (2003), as redes são, antes de qualquer coisa, formas de interação social, espaços sociais de convivência e conectividade. Definem-se 
essencialmente pelos intercâmbios dinâmicos entre os sujeitos que as formam. A autora sintetiza: "As redes são sistemas abertos e horizontais que aglutinam conjuntos de pessoas que se identificam com as mesmas necessidades e problemáticas"4. (GARCÍA, 2003, p.1, tradução nossa).

As redes sociais, segundo Souza (2009, p.12), "partem do conceito básico de horizontalidade, como uma malha, fios ligados horizontalmente, sem ganchos de sustentação". Lozares (1996, p.108, tradução nossa), por sua vez, explica que as redes sociais podem ser definidas "como um conjunto bem delimitado de atores-indivíduos, grupos, organizações, comunidades, sociedades globais, etc.- vinculados uns aos outros através de uma relação ou um conjunto de relações sociais" ${ }^{5}$.

Pode-se afirmar, então, que as redes sociais não se originaram a partir da Internet e nem surgiram com advento da Web $2.0^{6}$ e seus sites (Twitter, Blog, Facebook e outros). Estas são tão antigas quanto a história da humanidade, os primeiros agrupamentos humanos já desenvolviam relacionamentos em formato reticular.

\footnotetext{
Redes sociais complexas sempre existiram, mas os desenvolvimentos tecnológicos recentes permitiram sua emergência como uma forma dominante de organização social. Exatamente como uma rede de computadores conecta máquinas, uma rede social conecta pessoas, instituições e suporta redes sociais. (WELLMAN, 2002 apud RECUERO, 2009, p.93).
}

A Internet, como explica Castells (1999), tornou possível a virtualização das redes sociais, originando novas modalidades de conexões entre indivíduos e agrupamentos. Castells (2003), ao estabelecer uma compreensão da sociedade contemporânea, defende que a mesma é caracterizada por uma lógica estrutural baseada em redes. Dessa forma, a predominância deste padrão está em todos os setores da vida econômica e sociocultural.

Contemporaneamente, sites como o Twitter complexificaram a "Sociedade em Rede" e redimensionaram o conceito de redes sociais, uma vez que sua estrutura permite a interação entre pessoas e agrupamentos, dinamizando as relações existentes e criando outras.

216 Somanlu, ano 11, n. 1, jan./jun. 2011 
Tem-se, portanto, no Twitter a geração de redes sociais digitais (RSD), um novo paradigma gerado a partir da interação mediada por computador. As redes sociais digitais são proporcionadas por suportes virtuais, que são os sites de Redes Sociais (SRS). Os ambientes comunicacionais gerados pelos SRS "consistem num fenômeno de massa que está mudando a forma como todos nós criamos e usamos conteúdos publicados e circulados na Internet" (SOUZA, 2009, p.12).

\section{Capital social: demarcando o conceito}

Capital Social é um termo explorado por diversas áreas do conhecimento, destacando-se as aplicações no âmbito político, econômico e social. Embora tenha Alex Tocqueville como precursor (FRANCO, 2001), trata-se de uma discussão recente, notadamente da última década do século XX. Segundo Araújo (2010, p.12), Capital Social trata-se de um dos "conceitos mais importantes e mais controversos nas ciências sociais".

O conceito de capital social não é novo, mas a partir de estudos de Robert Putnam, publicado em 1993, com o título: Comunidade e democracia: $A$ experiência da Itália moderna, é que o tema tomou notoriedade e, a partir de 1990, foi utilizado pelo Banco Mundial. Segundo D’Araújo (2003, p.10, grifo nosso):

Passou a distinguir, na avaliação de projetos de desenvolvimento, quatro formas de capital: capital natural, que são os recursos naturais de que é dotado um país; capital financeiro, aquele produzido pela sociedade e que se expressa em infra-estrutura, bens de capital, capital financeiro, imobiliário, entre outros; capital humano, definido pelos graus de saúde, educação e nutrição de um povo; e finalmente, capital social, que expressa, basicamente, a capacidade de uma sociedade de estabelecer laços de confiança interpessoal e redes de cooperação com vistas à produção de bens coletivos. Segundo o Banco, capital social refere-se às instituições, relações e normas sociais que dão qualidade às relações interpessoais em uma dada sociedade. 
A concepção do Banco Mundial indica dois elementos básicos: laços de confiança interpessoal e redes de cooperação. Os laços são formas de interação entre os atores e o tipo de laço define como será a interconexão entre os envolvidos (RECUERO, 2009). As redes de cooperação entre os envolvidos, por sua vez, tem uma objetividade que é o bem comum.

A aquisição de capital social, de acordo com Boeira (2005, p.7), requer "hábito em relação a normas morais de uma comunidade, o que significa adquirir, no devido tempo de convívio, virtudes como lealdade, honestidade e confiabilidade." O capital social, assim, não pode ser alcançado pela ação individual, pois é baseado no predomínio de virtudes sociais e não apenas individuais.

Araújo (2010, p. 10) entende capital social como "a argamassa que mantém as instituições em contato entre si e as vincula ao cidadão visando a produção do bem comum". A compreensão metafórica da investigadora sintetiza o modo como trabalhamos o conceito neste trabalho, isto é, o capital social como um elemento conector entre os nós da rede, gerando a consistência necessária para manter as relações.

O capital social é um dos principais itens analisados nas redes sociais. Sousa (2007, p.120) afirma que a análise de redes sociais, como metodologia de pesquisa, "pode ser utilizada nessa abordagem do capital social e agora começa a tomar corpo nas pesquisas sociais e nas organizações".

Recuero (2009) faz um levantamento de distintas conceituações sobre capital social e destaca aspectos favoráveis e antagônicos. "Embora existam várias, as teorias a respeito do capital social diferenciam-se não no modo por meio do qual ele é construído, mas sobretudo em quem pode ter acesso a seus benefícios". (RECUERO E ZAGO, 2009, p.84).

A partir da discussão sobre o conceito, consideraremos o capital social como um conjunto de recursos de um determinado agrupamento que pode ser desfrutado por todos os membros do grupo, ainda que particularmente, e que está baseado na harmonia social. Ele está impregnado nas relações sociais e é determinado pelo conteúdo delas.

218 Somanlu, ano 11, n. 1, jan./jun. 2011 
Diante disso, Recuero (2009) afirma que ao estudar o capital social de uma rede social, é preciso examinar não apenas suas relações, mas, também, o conteúdo das mensagens que são trocadas através delas. A autora apresenta cinco elementos operadores (categorias) do conceito de capital social nas redes sociais:

a) relacional - que compreenderia a soma das relações, laços e trocas que conectam os indivíduos de uma determinada rede; b) normativo - que compreenderia as normas de comportamento de um determinado grupo e os valores deste grupo; c) cognitivoque compreenderia a soma dos conhecimentos e das informações colocadas em comum por um determinado grupo; d) confiança no ambiente social - que compreenderia a confiança no comportamento de indivíduos em um determinado ambiente; e) institucional - que incluiria as instituições formais e informais, que se constituem na estruturação geral dos grupos, onde é possível conhecer as "regras" da interação social, e onde o nível de cooperação e coordenação bastante alto (RECUERO, 2009).

Essas categorias de capital social tomam como base a classificação construída por Bertoline e Bravo (2001), que explicam que as redes sociais são naturalmente heterogêneas. Assim, o capital social pode ser percebido de formas diferenciadas nas diferentes ferramentas de rede social na Internet (Twitter, por exemplo) e a partir das formas de interação nos distintos sistemas.

\section{A pesquisa e procedimentos adotados}

Esse trabalho analisa o capital social nas conexões geradas na rede social digital do perfil do Twitter da Fundação Amazonas Sustentável (@FasAmazonas). Conforme aborda Recuero (2009, p. 30), as interações, na Internet, "são percebidas graças à possibilidade de manter os rastros sociais dos indivíduos, que permanecem ali”. Nesse sentido, a pesquisa foi realizada em três fases: 1. observações (assistemáticas e sistemáticas), 2. apreciação de perfis (seguido e seguidores) e 3. análise das atualizações. 
A observação assistemática das atualizações na "public timeline" do perfil da FAS teve como objetivo ter um primeiro contato com o objeto de estudo. Tem-se a vantagem de que: "essas interações são, de certo modo, fadadas a permanecer no ciberespaço, permitindo ao pesquisador a percepção das trocas sociais mesmo distantes, no tempo e no espaço, de onde foram realizadas" (RECUERO, 2009, p. 30).

Essa fase observacional foi de fundamental importância para determinar os procedimentos posteriores a serem tomados, além de dar condições para compreender a dinâmica da ferramenta. Posteriormente, foram feitas observações sistemáticas, por meio de protocolos. Assim, foram levantados aspectos fundamentais sobre nó principal da rede escolhida (o perfil @FasAmazonas) e analisados os perfis dos seguidores. Até o momento de nossa análise o perfil da FAS era seguido por 4.244 atores sociais (1. \%/10/11). A intenção era identificar as particularidades de cada nó da rede e identificar os principais tipos de interesse.

Em seguida, detemo-nos sobre a análise das conexões entre os diferentes agrupamentos de atores. Como destaca Recuero (2009, p. 54) "é preciso estudar o conteúdo dessas conexões, através do estudo de suas interações e conversações. Esse conteúdo pode sim auxiliar a compreender também a qualidade dessas conexões de forma mais completa”. Durante o período de observações (janeiro de 2010 a setembro de 2011) foram coletadas 300 atualizações que passaram por uma análise de conteúdo.

Para compreender como as conexões são estabelecidas e o nível de interatividade existente, levou-se em conta: valores envolvidos na atualização (Suporte Social, Laços Sociais, Reputação, Visibilidade, Acesso à informação, Popularidade e Conhecimento), a finalidade da atualização, o público a que se destina e a forma como é expressa.

Algumas particularidades nas atualizações foram identificadas, dessa forma puderam ser agrupadas em sete categorias: indicação de linkes, interação com o seguidor, informação sobre atuação da FAS, opinião de membro da FAS, notícia com base em fonte externa, declaração de líder de opinião pública e outros. A seguir apresenta-se a relação percentual entre as atualizações em cada categoria: 
Jonas Jr. | Denize Levy

Tabela 1. Capital social e número de atualizações nas categorias.

\begin{tabular}{|l|c|c|c|c|c|c|c|}
\hline Apropriação & \multicolumn{5}{|c|}{ Informacional } & \multicolumn{2}{c|}{ Conversacional } \\
\hline $\begin{array}{l}\text { Capital } \\
\text { Social }\end{array}$ & $\begin{array}{c}\text { Capital } \\
\text { Social } \\
\text { Institu- } \\
\text { cional }\end{array}$ & $\begin{array}{c}\text { Capital } \\
\text { Social } \\
\text { Relacio- } \\
\text { nal }\end{array}$ & $\begin{array}{c}\text { Capital } \\
\text { Social } \\
\text { Normativo }\end{array}$ & $\begin{array}{c}\text { Capital } \\
\text { Social } \\
\text { Cognitivo }\end{array}$ & $\begin{array}{c}\text { Capital } \\
\text { Social } \\
\text { Cognitivo }\end{array}$ & $\begin{array}{c}\text { Capital } \\
\text { Social } \\
\text { Relacio- } \\
\text { nal }\end{array}$ & $\begin{array}{c}\text { Varia- } \\
\text { dos }\end{array}$ \\
\hline $\begin{array}{l}\text { Categorias } \\
\text { Sobre } \\
\text { atuação }\end{array}$ & $\begin{array}{c}\text { Indica- } \\
\text { ção de } \\
\text { Link }\end{array}$ & $\begin{array}{c}\text { Opinião } \\
\text { de } \\
\text { membro }\end{array}$ & $\begin{array}{c}\text { Opinião } \\
\text { Pública }\end{array}$ & $\begin{array}{c}\text { Notícia } \\
\text { Externa }\end{array}$ & $\begin{array}{l}\text { Interação/ } \\
\text { seguidor }\end{array}$ & Outros \\
\hline $\begin{array}{l}\text { Atualizações } \\
\text { de Janeiro } \\
\text { de 2010 a } \\
\begin{array}{l}\text { Setembro } \\
\text { de 2011 (\%) }\end{array}\end{array}$ & $26 \%$ & $18 \%$ & $12 \%$ & $13 \%$ & $12 \%$ & $14 \%$ & $5 \%$ \\
\hline
\end{tabular}

Fonte: Jonas Gomes Jr.

Uma das formas predominantes de uso do Twitter da FAS vincula-se ao Capital Social Institucional (que inclui as instituições formais e informais, no qual e possível conhecer as "regras" da interação social) e está na categoria Informação sobre atuação da FAS, que corresponde a $26 \%$ dos tweets analisados. Inclui-se uma variedade de atualizações, como essas notícias sobre atuação da entidade:

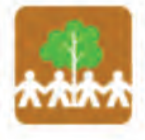

Amazonas Sustentável @FasAmazonas

I Oficina de Capacitação das Escolas dos Núcleos de Conservação e Sustentabilidade capacita professores e gestores http://migre.me/3Yfd6

Figura 1. Exemplo 1 da Categoria Informação sobre Atuação da FAS. Fonte: http://twitter.com/\#!/fasamazonas

\section{Amazonas Sustentável PasAmazonas}

A página da FAS no Facebook atingiu 1.000 pessoas que a curtiram. Muito obrigado! www.facebook.com/fasamazonas

Figura 2. Exemplo 2 da Categoria Informação sobre Atuação da FAS.

Fonte: http://twitter.com/\#!/ fasamazonas 
Ainda na categoria informação sobre atuação da FAS, incluíram-se as atualizações simultâneas sobre os eventos organizados pela entidade ("Eron Bezerra, ex-secretário de Produção Rural, participa da Conversas com a FAS neste momento, e fala sobre desenvolvimento no campo | Thu May 20 2010", "Conversas com a FAS: 'a ecola [sic] deve ser uma incubadora de micro-empreendimentos', diz Martin Burt" | Wed May 26 2010). Com esses exemplos, evidencia-se que nesta categoria existe uma intenção clara da FAS em auto referenciar-se. A diversidade de formas utilizadas para fazer isso auxilia na construção de uma imagem positiva da entidade frente aos seus seguidores.

Entende-se que o Capital Social Relacional (que compreende a soma das relações, laços e trocas que conectam indivíduos de uma determinada rede) é expresso por meio da Categoria indicação de links (18\%), visto que equivale às atualizações que sugerem ao seguidor o redirecionamento para outras ambiências digitais que guardam relação direta com a área de atuação da entidade. Pode-se exemplificá-la por meios destes tweets:

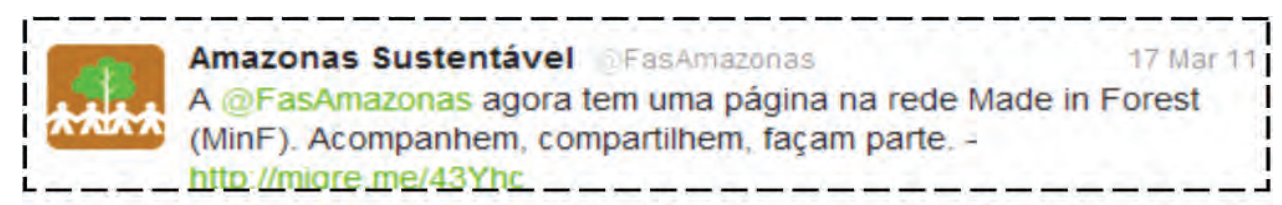

Figura 3. Exemplo 1 da Categoria Indicação de links.

Fonte: http://twitter.com/\#!/ fasamazonas

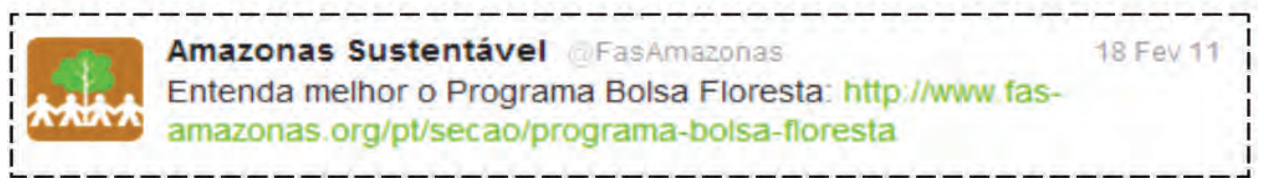

Figura 4. Exemplo 2 da Categoria Indicação de links.

Fonte: http://twitter.com/\#!/ fasamazonas

Acredita-se que o Capital Social Relacional é fundamental para constituição da Rede Social Digital e que ocorre uma utilização adequada desta categoria para os propósitos de interlocução da FAS com os seus seguidores,

222 Somanlu, ano 11, n. 1, jan./jun. 2011 
visto que a indicação de links proporciona aos seguidores uma seleção de informações sobre a entidade e assuntos que são potencialmente interessantes para quem segue a conta.

Outra estratégia utilizada na tentativa de construção de uma imagem positiva foi verificada nos tweets da categoria Opinião de membro da FAS (12\%), que corresponde ao Capital Social Normativo (que compreenderia as normas de comportamento de um determinado grupo e os valores deste grupo). Nessas atualizações as ideias, pensamentos, assertivas dos membros organização são citadas:

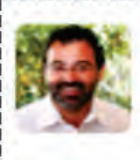

Virgilio Viana -virgilio_viana

25 Fev 11

Fiz uma participação especial no documentário "Carbono \& Metano",

leiam mais no meu Blog http: $/ /$ migre me/3WFhQ \#sustentablilidade

ol Retweetado por Amazonas Sustentável

Figura 5. Exemplo 1 da Categoria de Opinião de Membro da FAS.

Fonte: http://twitter.com/\#!/ fasamazonas

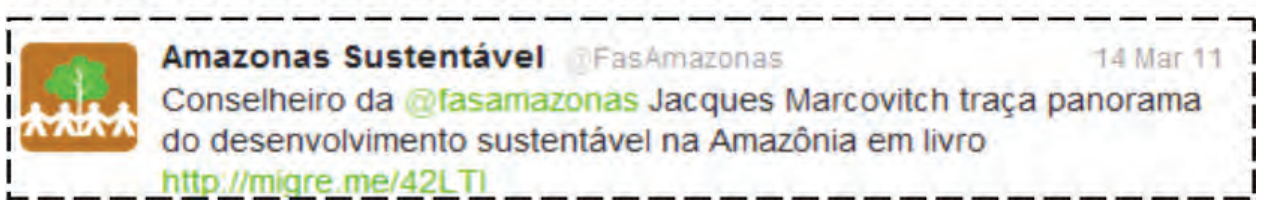

Figura 6. Exemplo 2 da Categoria de Opinião de Membro da FAS.

Fonte: http:// twitter.com/\#!/ fasamazonas

Há nessa categoria a questão do discurso de autoridade, na qual há pessoas que estão "autorizadas" para falar porque detém um conhecimento específico sobre algo. A disseminação das opiniões dos membros da FAS pode ser considerada estratégica, pois além de posicionar os ideais da FAS frente a diversas questões, apresentando pontos de vistas de pessoas institucionalizadas, contribui para gerar uma imagem de entidade com filosofia própria e autônoma. 
Outra categoria, a Declaração de líder de Opinião Pública (13\%), também está ligada ao discurso de autoridade, contudo as atualizações destacam considerações sobre questões ambientais ou comentários sobre a atuação da FAS feitas por líderes de opinião pública (jornalistas, ambientalistas, empresários, dentre outros).

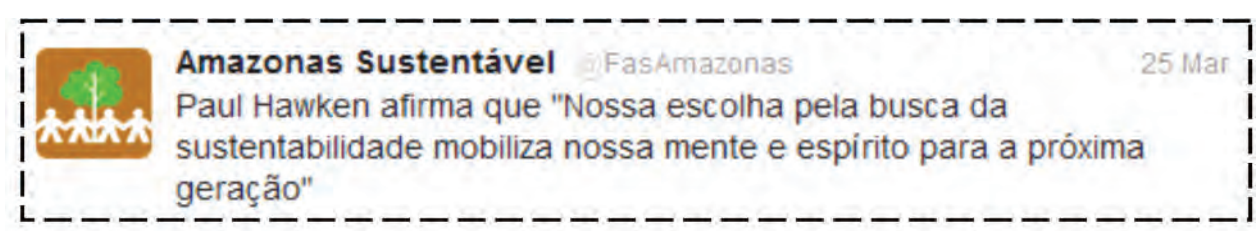

Figura 7. Exemplo 1 da Categoria Declaração de Líder de Opinião Pública.

Fonte: http://twitter.com/\#!/fasamazonas

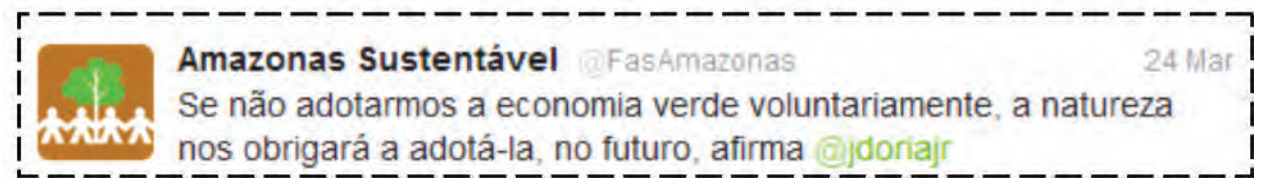

Figura 8. Exemplo 2 da Categoria Declaração de Líder de Opinião Pública.

Fonte: http://twitter.com/\#!/fasamazonas

Nesse aspecto relacionamos diretamente ao Capital Social Cognitivo (que compreende a soma do conhecimento e das informações colocadas em comum por um determinado grupo). Acredita-se que a utilização destas atualizações com citações pode ser considerada uma forma de legitimar as ações desenvolvidas pela entidade, assim como uma forma de disseminar posicionamentos que tenham afinidade aos da FAS.

O Capital Social Cognitivo também está na categoria Notícia com base em fonte externa $(12 \%)$ refere-se às atualizações feitas a partir de fontes noticiosas externas e replicações de conteúdo considerado noticioso: 
Você sabia que o Estado do Amazonas criou a primeira lei sobre Mudanças Climáticas (Lei Estadual $\mathrm{n}^{\circ} 3135$ de 2007)?

\#SemanaMeioAmbiente

Figura 9. Exemplo 1 da Categoria Noticia com base em fonte externa.

Fonte: http://twitter.com/\#!/ fasamazonas

Esse tipo de recurso demonstra uma conformidade com os interesses dos seguidores da entidade e cumpre um papel de disseminação de informações noticiosas ligadas as questões ambientais.

A seguir alguns exemplos de Capital Social Relacional (que compreende a soma das relações, laços e trocas que conectam indivíduos de uma determinada rede) por meio da categoria interação com o seguidor (14\%), na qual a entidade estabelece um contato direto com seus seguidores.

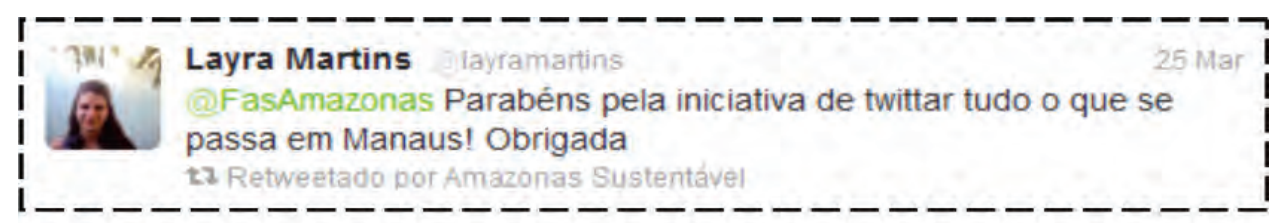

Figura 10. Exemplo 1 da Categoria Interação com o seguidor.

Fonte: http://twitter.com/\#!/fasamazonas

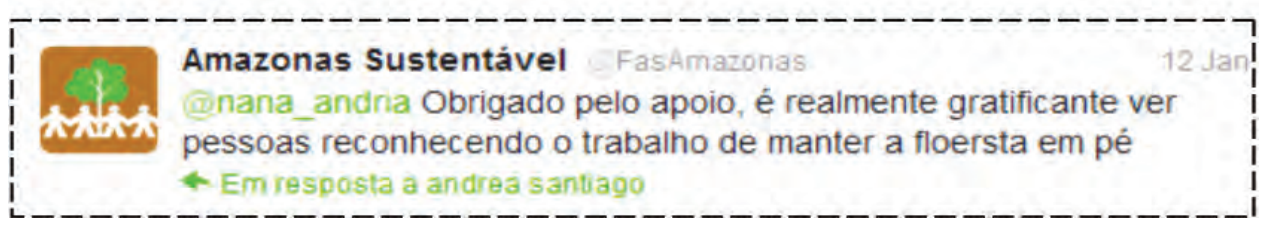

Figura 11. Exemplo 2 da Categoria Interação com o seguidor.

Fonte: http://twitter.com/\#!/fasamazonas

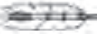

Somanlu, ano 11, n. 1, jan./jun. 2011225 
Apesar desses tweets estarem na mesma categoria, foram gerados a partir de motivações diferenciadas: responder um questionamento, agradecer uma replicagem (ação que visa reproduzir o conteúdo da atualização a todos os seguidores de determinada conta) ou fazer esclarecimentos diversos. Essa forma de utilização é considera fundamental, pois trata-se de a uma interação direta na qual a entidade precisa estar aberta a todo tipo de diálogo. Dentre os exemplos acima, há o caso de um seguidor que questionou as motivações da existência do perfil da FAS, conseqüentemente, a responsável pela atualização precisou se posicionar no micro blog frente a essa situação, mas não rebatendo de forma contundente.

Em uma última categoria, denominada Outros (05\%), destacam-se as atualizações que não se encaixam nas descrições acima. Por exemplo, esta: "Sigam o@institutoethos e acompanhem online as novidades. | Wed May 12 2010". Trata-se de um tipo de twitte pouco recorrente e por recomendar para seguir, vincular-se ao perfil de outro, não foi incluída como parte de nenhuma das categorias estabelecidas.

Como ficou evidenciado, as atualizações com o Capital Social Institucional (Sobre a atuação da FAS) são predominantes (26\%), todavia, é preciso explicitar que algumas atualizações das categorias indicação de links $(18 \%)$ e Opinião de membro (12\%) foram contabilizadas juntamente com aquela primeira, pois guardavam características que permitia a colocação em ambas categorias.

Como um exemplo significativo disso, tem-se a atualização: "Confira o texto completo, publicado no Dia do Meio Ambiente no Jornal Brasil Econômico: link | Mon Jun 7 2010)". Trata-se de um redirecionamento para o texto do superintendente da FAS, Virgílio Viana, sobre a conservação das florestas tropicais em um site. Tal Twitter relaciona-se diretamente com a categoria Opinião de membro da FAS, Indicação de link e Atuação da FAS, demonstrando que as diferentes formas de Capital Social (Relacional, Normativo, Cognitivo e Institucional) relacionam-se umas com as outras. 


\section{Análise dos resultados}

Notou-se que no perfil @FasAmazonas há um denso circuito comunicativo em virtude das diferentes formas de Capital Social que, por sua vez, indicam valores díspares e manifestos (Popularidade, Reputação, Conhecimento e Visibilidade, Acesso à informação, Suporte Social e Laços Sociais). Percebe-se que há uma complexidade no sistema social da FAS, visto que uma série de interesses envolvidos, que são expressos por meio das diferentes formas de Capital Social.

Os valores envolvidos nessa complexa trama envolvem motivações e interesses que cercam as atualizações partem principalmente para o acesso à informação qualificada. As porcentagens obtidas na nossa pesquisa, por exemplo, indicam que a maioria dos tweets coletados continha algum tipo de conteúdo informativo. Entende-se que não há, nesse aspecto, uma atualização com intuito de meramente informar, mas também persuadir e construir uma imagem positiva da entidade.

O entendimento de que há uma complexidade inerente ao Twitter nos coloca, por exemplo, as inter-relações entre o fator ideológico e o capital social. O Capital Social Institucional $(26 \%)$ representa uma tentativa da FAS se auto legitimar no Ciberespaço. O falar bem de si próprio, apesar de indicar uma autopromoção, é uma forma de garantir sua permanecia na comunidade ambiental. Assim, cada atualização institucional é uma marca no sistema social, ajuda a construir um ambiente favorável à instituição.

A investigação sobre o perfil do Twitter da FAS indica ainda que o Capital Social está relacionado à qualidade de informações sobre a questão ambiental. O acesso dos seguidores a informações sobre a Amazônia, Sustentabilidade, Desenvolvimento Sustentável, Ecologia e outros aspectos indica que se trata de um dos principais motivos para seguir o perfil. O Capital Social Cognitivo do perfil é apontado por meio do acesso às informações ambientais, somando-se as categorias "Opinião Pública" e "Notícia Externa" tem-se $25 \%$ (a $2 .^{\circ}$ maior porcentagem). 
A veiculação de conteúdo informacional parece ser o enfoque do perfil da FAS, pois, como se pode perceber na Tabela 1, a maioria das categorias (Sobre atuação, Indicação de links, Opinião de membros, Opinião pública e Notícia externa) somam 81\% das formas de utilização. Recuero e Zago (2009, p. 7) explica que "no Twitter, esse potencial parece elevado, uma vez que novas conexões representam um baixo custo para o ator social e parece haver um investimento ativo dos atores em produzir novas e especializadas informações".

Foi comum, por exemplo, durante a pesquisa encontrar informações sobre questões ambientais, de forma que essa categoria consistia em qualificação das informações. Tweets que trazem informações são especialmente úteis à complexidade da rede social, visto que permitem o acesso a novas informações, a novas discussões e, por isso, auxiliam na construção do conhecimento.

Além disso, foi possível verificar que muitos atores republicavam informações que recebiam para seus seguidores, quase sempre utilizando a sigla "RT" ou "RTT" (para "retweeting" ou "retwittando"). Embora apenas 21 tweets com essas características tenham sido recolhidos, essa prática sugere que o Twitter é um ambiente no qual se busca e se repassa informação. A preocupação com a relevância das informações publicadas está diretamente relacionada à busca por reputação, que também pode ser construída por meio da difusão de informações.

Tais observações reforçam a apropriação do Twitter da FAS como ferramenta de coleta e difusão de informações ambientais e sugere que muitos usuários estão no sistema para receber informações consideradas relevantes, que poderão ou não ser repassadas a outras ambiências digitais (Facebook, por exemplo). Nota-se ainda que a busca pela reputação também está relacionada com a qualidade das informações divulgadas na conta@FasAmazonas

\section{Considerações finais}

A partir da pesquisa realizada, concluiu-se que a "argamassa" que mantém o vínculo entre a Fundação Amazonas Sustentável (FAS) e seus se-

228 Somanlu, ano 11, n. 1, jan./jun. 2011 
guidores é o Capital Social Cognitivo, manifestado na propriedade informacional das atualizações. Nesse aspecto, os vínculos sociais estabelecidos podem ser considerados fortes, visto que há uma clara decisão dos seguidores em estarem informados sobre as causas ambientais, especificamente no Amazonas.

Entende-se que há uma evidente necessidade de aumentar o Capital Social Relacional, ou seja, a interação direta com o seguidor. A falta de interação gera uma tendência para que os nós da rede se afastem ou migrem para outras ambiências digitais. A interação direta com os seguidores gera a consistência necessária para fortalecer as relações sociais. Ressalta-se que o capital social precisa ser baseado no predomínio de virtudes coletivas e não apenas individuais.

Pode-se ainda inferir que, com o tempo, as conexões estabelecidas de forma reativa (mantidas apenas pelo sistema)no@FasAmazonas poderão perder força, demonstrando certo artificialismo nas estruturas sociais apresentadas, ou seja, as conexões estabelecidas nada mais representarão do que números de seguidores.

Contrariando essa perspectiva, o Twitter tem potencial para efetivar o aprimoramento no relacionamento com os diversos seguidores, pois esses são, hoje, mais diversificados e, principalmente, mais exigentes quanto ao relacionamento, ou seja, cada seguidor quer ter oportunidade de diálogo aberto, transparente e deseja ter vez e voz nas discussões.

O movimento ambientalista necessita, portanto, adaptar-se às condições de comunicação digital apresentadas pelo novo paradigma tecnológico, em específico as mídias sociais, como o microblog twitter. O estudo de caso sobre o Twitter da Fundação Amazonas Sustentável contribui para evidenciar que o contexto atual, de emergência dos sites de mídias sociais, como Orkut, Fotolog, Facebook, Blog, Twitter, e a expansão da sociabilidade nos ambientes ciber criam um cenário desafiador para Comunicação Organizacional e as organizações ambientais. 


\section{Notas}

${ }^{3}$ É uma forma de publicação de arquivos de mídia digital, como áudio, vídeo, foto, pela Internet, por intermédio de uma lista de links, conhecidas como "feed RSS", disponibilizada em alguns sites. Dessa forma, aqueles que seguem as listas podem acompanhar a atualização de determinado site e/ou baixar arquivos do mesmo.

${ }^{2}$ É uma Organização da Sociedade Civil de Interesse Público (OSCIP), instituição públicoprivada, sem fins lucrativos e não governamental. A FAS está relacionada com a manutenção de serviços ambientais e desenvolve duas atividades principais: o Programa Bolsa Floresta (PBF) e o projeto de Redução de Emissões por Desmatamento e Degradação (REDD) da Reserva de Desenvolvimento Sustentável (RDS), especificamente a do Juma.

${ }^{3} \mathrm{O}$ artigo apresenta os motivos que levaram a Fundação Amazonas Sustentável (FAS) a utilizar o microblog Twitter e as formas de sua apropriação.Com base na pesquisa realizada, conclui-se que os fatores determinantes para a escolha da utilização do Twitter não estão relacionados ao modismo e que existem sete formas predominantes na utilização do microblog pela FAS.

${ }^{4}$ Tradução livre de: "Las redes son sistemas abiertos y horizontales, y aglutinan a conjuntos de personas que se identifican con las mismas necesidades y problemáticas". (GARCÍA, 2003, p.1).

5 Tradução livre de: como un conjunto bien delimitado de actores-individuos, grupos, organizaciones, comunidades, sociedades globales, etc.- vinculados unos a otros a través de una relación o un conjunto de relaciones sociales.

${ }^{6} \mathrm{~A}$ Web 2.0 é a segunda geração de serviços online e caracteriza-se por potencializar as formas de publicação, compartilhamento e organização de informações, além de ampliar os espaços para a interação entre os participantes do processo. (PRIMO 2007, p.1).

\section{Referências}

ARAUJO, Maria Celina Soares. Capital Social. 2.ed. Rio de Janeiro: Zahar, 2010.

BERTOLINI, S.; BRAVO, G. Social Capital, a Multidimensional Concept. University of Exeter, 2001 Disponível em < http://www.ex.ac.uk/shipss/ politics/research/socialcapital/other/bertolini.pdf> Acesso em 12 set 2010.

BOEIRA. Ética empresarial \& capital social: aproximações conceituais. Revista Internacional Interdisciplinar INTERthesis, Florianópolis, Santa Catarina, v. 2, n. 2, 2005. Disponível em: <http://journal.ufsc.br/index.php/interthesis/ article/viewFile/730/10789>. Acesso em 12 out. 2011. 
CASTELLS, Manuel. A galáxia da internet: reflexões sobre a internet, os negócios e a sociedade. Rio de Janeiro: Jorge Zahar, 2003.

- A sociedade em rede. A era da informação: economia, sociedade e cultura. São Paulo: Paz e Terra, 1999. v.1

COGO, Denise; BRIGNOL, Liliane Dutra. Redes sociais e os estudos de recep̧cão na internet. In: Matrizes, revista do Programa de Pós-Graduação em Ciências da Comunicação da Universidade de São Paulo. Ano 4, n. 2 (jan./jun.2011). São Paulo: ECA/USP: 2011.

FELINTO, Erick. Em busca do tempo perdido: o sequestro da história na cibercultura e os desafios da teoria da mídia. In: Matrizes, revista do Programa de Pós-Graduação em Ciências da Comunicação da Universidade de São Paulo. Ano 4, n. 2 (jan./jun.2011). São Paulo: ECA/USP: 2011.

FRANCO, A. Capital social: leituras de Tocqueville, Jacobs, Putnam, Fukuyama,Maturana, Castells e Levy. Brasília: Instituto de Política Millennium, 2001.

GARCÍA, Marta Rizo. Redes: una aproximación al concepto. Sistema de Información Cultural, CONACULTA, 2003. Disponível em: <http:// sic.conaculta.gob.mx/centrodoc_documentos/62.pdf>. Acesso em 12 out. 2011.

GOMES JR, Jonas da Silva; LEVY, Denize Piccolotto Carvalho. @FasAmazonas: um estudo de caso sobre o uso do microblog Twitter. In: Maria Ataide Malcher, Netilia Silva dos Anjos Seixas, Regina Lúcia Alves de Lima e Otacílio Amaral Filho (Orgs). Comunicação Midiatizada da Amazônia. Belém: Fadesp, 2011.

LOZARES, Carlos. La teoria de redes sociales. Papers. n. 48, 1996. Disponível em: < http://ddd.uab.es/pub/papers/02102862n48/ 02102862n48p103.pdf>. Acesso em 19 out. 2011.

O'REILLY, T; MILSTEIN, S. Desvendando o Twitter. Trad. Eduardo Fraguas. São Paulo: Digerati Books, 2009. 
PRIMO, A. O aspecto relacional das interações na Web 2.0. E- Compós (Brasília), v. 9, p. 1-21, 2007. Disponível em< http://www6.ufrgs.br/limc/PDFs/ Web2.pdf $>$ Acessado em 12 out. 2011.

PUTNAM, R. Comunidade e democracia. A experiência da Itália moderna. Rio de Janeiro: Ed. Fundação Getúlio Vargas, 1996.

RECUERO. Raquel. Redes sociais na Internet. Porto Alegre: Editora Sulina, 2009.

RECUERO, Raquel; ZAGO, Gabriela. Em busca das "redes que importam": redes sociais e capital social no Twitter. Líbero, Brasil, v. 12, n. 24, p. 81-94, 2009. Disponível em<http://www.revistas.univerciencia.org/index.php/libero/article/view/6787>. Acessado em 12 out. 2011.

SOUSA, Paulo de Tarso Costa de. Metodologia de análise de redes sociais. In: MUELLER, Suzana Pinheiro Machado (org). Métodos para pesquisa em Ciência da Informação. Brasília: Thesaurus, 2007.

SOUZA, Sérgio Freire. As redes sociais e a liquidez na Sociedade 140 bytes: sob os olhos da Coruja de Minerva. XIV Semana de Letras da Universidade Federal do. Amazonas, Manaus, 2009. Disponível em: < http://www.sergiofreire.com.br/ academicos/redessociais140bytes.pdf>. Acessado em 12 out. 2011.

WELLMAN, B. The Networked Nature of Community Online and Offline. IT \& Society n.1, vol1, p.151-165. Summer, 2002. 